\title{
Assessing Equine Emotional State
}

\author{
Carol Halla, Hayley Randle ${ }^{b}$, Gemma Pearson ${ }^{c}$, Liane Preshaw ${ }^{d}$, Natalie Waran ${ }^{\mathrm{e}}$ \\ a School of Animal, Rural and Environmental Sciences, Nottingham Trent University, Brackenhurst \\ Campus, Southwell, Nottinghamshire, NG25 OQF, UK \\ b School of Animal and Veterinary Science, Charles Sturt University, Wagga Wagga, 2678, NSW, \\ Australia \\ ${ }^{c}$ Royal (Dick) School of Veterinary Studies, The University of Edinburgh, Easter Bush, Roslin, \\ Midlothian, EH25 9RG, UK \\ ${ }^{\mathrm{d}}$ The Horse Trust, Princes Risborough, Bucks, HP27 OPP, UK. \\ e The Faculty of Education, Humanities and Health Sciences, Eastern Institute of Technology, \\ Napier 4112, New Zealand \\ Corresponding author: Carol Hall Carol.hall@ntu.ac.uk
}

\section{Abstract}

The scientific study of animal emotion has recently become an important focus for animal behaviour and welfare researchers. For horses used by humans for work, recreation or sport, the question of the significance of their life experiences in terms of their emotional response, is an important one if we are to provide for their welfare needs. Horses have received relatively less scientific attention than many livestock species when it comes to investigating emotional state or affective experience, although their behavioural responses during sporting or recreational performance are often described anecdotally using terminology indicating an underlying presumption of equine emotions. Indeed, the international governing body for equestrian sport, the Fédération Equestre Internationale (FEI), include the concept of 'the Happy Equine Athlete' into their rules, as a key objective during training and competition.

This review presents available evidence to date of the physiological, behavioural and cognitive components of equine emotion and evaluates the extent to which the question concerning 'how horses feel' can be answered. The characterization of equine emotion in terms of level of arousal and valence, based on physiological, behavioural and cognitive indicators, offers a way forward to determine the impact of different situations and experiences on horses during their working lives. There is a need to develop robust validated methods for accessing equine emotions, to underpin a universally agreed method for/approach to providing an accurate assessment of equine welfare that can be utilized in a variety of contexts. This will 
provide a means of monitoring and improving the horse's experience, ensuring that the horse enjoys a good life, rather than one that is just worth living.

Key words: Equine; horse; emotion; welfare; behaviour; cognition

\section{Introduction}

The study of animal behaviour has increasingly included consideration of the emotional component of behavioural responses, with the ultimate goal of being able to assess subjective experience, that is, how the animal feels. For horses used by humans for work, recreation or sport, this is important if we are to provide for their welfare needs. A framework for objectively assessing equine emotional states has yet to be developed. There is a need for validated indicators of negative and positive emotions that can be applied during work, training and performance, both at any one point in time and for the duration of their lives.

There has been much debate surrounding the ethical use of the horse in sport, and when this use may become abuse (Campbell, 2013). The impact of training, competitive demands and management practices have been evaluated to differing extents (for example, Schmidt et al., 2010; Peeters et al., 2013; Yarnell et al., 2015), with the focus of many studies being on technological advances to measure the physical impact of specific pieces of equipment, the rider's actions and training methods (see Derksen and Clayton, 2007; Randle et al., 2017). There has been less focus on the development of methods for assessing the subjective experience of the horse. However, anecdotally there is an underlying presumption of equine emotions. For example, the Fédération Equestre Internationale (FEI) have recently incorporated the concept of 'the Happy Athlete' into their rules, as a key objective during dressage training, in competition and to be rewarded by judges (FEI, 2009). In addition, many animal welfare advocates promote positive welfare suggesting that animals should not only be free from negative emotions, but also experience positive ones (for example, World Society of Aquariums and Zoos, 2015). 
In this review we consider the evidence for equine emotion and evaluate the potential offered by a range of research tools for assessing the subjective experience of the horse.

\section{Animal emotion, natural selection and the horse-human relationship}

As a means of characterizing the subjective emotional experiences of animals, a two-dimensional 'core affect' approach has been proposed (see Mendl et al., 2010). Animals' subjective emotional experiences can be characterized according to valence (e.g. positive or negative, rewarding or punishing, pleasant or unpleasant) and arousal/intensity level (e.g. contentment versus excitement) (Mendl et al., 2010; Paul et al., 2005). In humans, the reported subjective experiences of core affect are accompanied by neural, behavioural, physiological and cognitive changes that can be measured objectively (Mendl et al., 2010). Whilst we cannot be sure if animals experience the conscious, subjective component of emotions (Mendl et al., 2010; Paul et al., 2005), the behavioural, physiological and neural changes associated with emotion-inducing occurrences are adaptive (Paul et al., 2005).

The survival advantage of emotional responses relates to the effect that they have on subsequent behavioural motivation (motivational intensity), determining whether the animal approaches or avoids a stimulus or situation. This distinction is central to understanding both the function and the behavioural consequences of emotion and is clearly demonstrable (Elliot et al., 2013). It also provides a means of assessing the valence of an emotion (Colombetti, 2005). Approach behaviours are generally indicative of expectations of positive outcomes, linked to appetitive behaviour, reward seeking and positive appraisal of stimuli; whilst avoidance behaviours orient the animal away from aversive stimuli and the threat of negative consequences (Elliot et al., 2013). The motivation to either approach or avoid has also been used to differentiate between two potentially negatively valenced emotions, those of fear (avoidance) and aggression (approach) (Mauss and Robinson, 2009). In addition, in terms of contributing to the assessment of mental state in animals, an absence of motivation, as demonstrated in depressed / withdrawn animals, must also be considered (McBride et al., 2017). 


\subsection{Natural Selection of equine emotion}

The horse's behavioural repertoire evolved in response to challenges faced in its evolutionary niche (Cooper and Albentosa, 2005) as a naturally free-ranging, social, grazing herbivore (Cooper and Mason, 1998). Under natural conditions, horses live in stable social groups (Boyd and Keiper, 2005), an important survival strategy (Goodwin, 1999). Group cohesion is enhanced by affiliative behavioural interactions such as mutual grooming, the latter having been shown to reduce heart rate, a sign of relaxation and positive affect (Feh and De Mazières, 1993). In contrast, social instability can result in increased inter-individual aggression (potentially resulting in negative valence, high arousal states), as demonstrated in young domestic horses that were repeatedly re-grouped (Christensen et al., 2011). When assessing equine husbandry, the relationship between social grouping and equine emotional state is an important factor (Van Dierendonck and Spruijt, 2012) and offers an additional perspective on ways to improve equine welfare (Špinka, 2012).

As a survival strategy, the within-group transfer of positive emotion contributes to group stability (Feh, 2005), and reduces unnecessary energy expenditure and risk of injury. For a prey species such as the horse, the rapid transfer of fear and the resultant group avoidance behaviour (flight response) is also important for survival (Cooper and Albentosa, 2005). It has been demonstrated (in mice) that observing other individuals suffering from aversive stimuli can result in fear and associated behavioural responses (Jeon et al., 2010). This empathetic-type response would facilitate survival and is likely to occur in other species, including the horse. However, in terms of survival (in prey species in particular) there are advantages in hiding emotions that are suggestive of vulnerability (to predation or social rejection) (McFarland, 1999). This potential lack of expression poses an additional challenge in recognising signs of emotion in the horse.

Natural selection has resulted in three underlying features of equine emotion. Firstly, group composition and behaviour is intrinsically linked to individual emotional well-being. Secondly, the transfer of emotion between individuals has both rapid, short term consequences as well as longer term impact on emotional state. Finally, and potentially the most pertinent in terms of assessing equine 
emotion, survival is enhanced by masking underlying emotion. The challenge is to identify signs that cannot be hidden by the horse.

\subsection{Emotion, welfare and the horse-human relationship}

As with the field of animal welfare, human research suggests that there are many different views on what is meant by well-being or welfare, and in human literature, this is described as an abstract concept referring to the state of a person's life (Clark and McGillivray, 2007). In the animal field there seems to be agreement that welfare or well-being is considered to be a multidimensional phenomenon based upon life experiences and circumstances, characterized by how an individual feels and functions. Since animals share the same central and peripheral neural mechanisms involved in experiencing emotion in humans, and will actively seek resources and situations assumed to provide them with a pleasurable experience and explicitly avoid situations that might be assumed to be negative, it seems likely that they experience similar emotional states. As such, there is some value to the subjective assessment of how animals 'feel'.

Subjective judgements about an animal's emotional state based on animal body language were used in the free choice profiling methodology developed by Wemelsfelder et al. (2001). This methodology has evolved and includes the development of lists of species-specific descriptors that can be used to assess emotional state, now termed Qualitative Behavioural Assessment (QBA) (see Wemesfelder et al., 2000; Wemelsfelder et al., 2001; Wemelsfelder and Mullan, 2014). A number of studies have sought to validate this QBA approach, with inter-observer agreement being tested as well as comparisons with other behavioural assessments (for example, Minero et al., 2009; Napolitano et al., 2008; Fleming et al., 2013; Minero et al., 2016). However, as both the subjective assessment and comparative measures are frequently based primarily on the behavioural expression of the animal, this approach requires further validation before it can be applied as a stand alone method of assessing emotional state. Comparisons with appropriate physiological measures provide more convincing support in some cases (for example, Stockman et al., 2011). The future development of a fixed list of descriptors, backed up with objective (physiological) evidence would be valuable in terms of providing an accessible means of assessing equine emotional state. 
Horse-human interactions undoubtedly influence both the subjective emotional experience and the behavioural expression of the horse. The influence may be due to the intensive management, handling and focused interaction associated with the process of training, and the physical and emotional demands placed on the animal in relation to performance. Methods of training and handling which provoke negative emotions and states such as fear, or where the individual experiences pain, may lead to short term success in relation to behavioural change, but will also produce fearful horses which are not desirable for the horse or human safety, nor successful for performance in the longer term. When frightened or anxious, horses will show escape responses ranging from agitation involving a raised head and neck to extreme reactions including bolting. A report looking at horse related injuries, found that $70 \%$ of the self-reported accidents in the UK involving horses, were due to the horse's behaviour (Silver et al., 1991). There is a need to understand how to avoid provoking negative emotions in horses during handling and training to reduce fear and improve human safety.

Domestic horses are generally protected from predation, provided with sufficient food and sheltered from climatic extremes, but the psychological need to respond to these factors still exists and can lead to behavioural responses that are not seen in the horse's natural environment, for example apathy and unresponsiveness (Cooper and Albentosa, 2005). Horses may experience withdrawn, depressive-like states, which include reduced reactivity to environmental stimuli (Fureix et al., 2015; Rochais et al., 2016). These maladaptive behaviours indicate that some aspects of the domestic environment pose challenges to which the horse may not be able to adapt (Cooper and Albentosa, 2005). For a review of management and training factors that can result in depression (and signs indicative of 'learned helplessness') see Hall et al. (2008).

\section{Components of emotion}

In human literature, emotion is broadly defined as an innate, intense but shortlived response to an event (internal or external) that has behavioural, physiological (autonomic), subjective and cognitive (appraisal) components (Panksepp, 2005; Paul et al., 2005; Boissy et al., 2007; Garland et al., 2010; de Waal, 2011). Also in humans, emotional state is thought to relate to the total of positive vs negative emotional experiences during the medium to long term, and 
mood state can be intentionally manipulated through cognitive or chemical means to improve a person's quality of life (Garland et al., 2010). Research into reliable indicators of emotion in horses is an important first stage towards understanding their longer term emotional state and consequently welfare.

In addition to the lack of validated methodologies, there is the complication of previous experience affecting individual emotional responses, both in terms of how situations are appraised and the subsequent response. Indeed the behavioural and physiological responses of horses may not reflect a specific emotion since changes as a result of learned associations can cause high behavioural arousal and associated changes in physiology (Innes and McBride, 2008), all of which could relate to a negative or positive emotional state. A further concern is that changes related to positive emotional responses are generally considered more subtle and somewhat variable (Boissy et al., 2007). This explains why up until now, only a very few studies have explicitly focused on trying to assess positive emotions in horses (for example, Stratton et al., 2010). To address the challenges associated with interpreting equine behaviour in relation to emotional state a combination of physiological measures with behavioural observations (for example, Hall et al., 2014; Yarnell et al., 2013) is recommended in order to gain more conclusive information.

\subsection{Physiological components of emotion}

Emotional responses in animals relate to changes in physiological arousal mainly mediated via the autonomic nervous system (ANS) and hypothalamic-pituitaryadrenal (HPA) axis (Weiten, 1992). Adaptive physiological responses may result in changes in: heart rate (HR), blood pressure, respiratory rate, pupil size, perspiration, corticosteroid levels and neuro-chemicals (Fraser, 2008). These are similar to changes seen in humans (Ekman et al., 1983; Levenson, 1992) and evidence of the relationship between physiological profiles and subjective human emotional experience offers one means of getting closer to identifying emotion in animals.

In humans, a meta-analysis of 22 ANS measures of emotion found some evidence that cardiovascular parameters could differentiate between positive and negative emotions (Cacioppo et al., 2000). More recently, 11 concurrent cardiovascular, electrodermal and respiratory measures were found to differentiate (with an 
accuracy of $85 \%$ ) between fear, sadness and neutral emotional responses to watching films, matched for arousal and valence (Kreibig et al., 2007). Although in general ANS activity reflects arousal, but not necessarily valence in emotional responses (Mauss and Robinson, 2009), some variation has been found in relation to specific emotional states in humans. For example activation of the sympathetic branch results in adrenaline and noradrenaline release from the adrenal medulla; and although both hormones increase arousal, adrenaline is more closely associated with negative emotions such as anxiety and fear (Abelson et al., 1996; Fell et al., 1985).

Heart rate variability (HRV) appears to be a good indicator of short term psychophysiological stress, anxiety, calmness and other emotional responses of both positive and negative valence in people (Beauchaine, 2001; CatipovicVeselica et al., 1999; Cerutti and Mainardi, 1995; Figueroa, 2007; McCraty et al., 1995; McCraty et al., 1998; Porges et al., 1996; Sleigh and Henderson, 1995). In one study evaluating pre surgical anxiety of human patients with hepatic cancer, HRV analysis indicated increased anxiety levels immediately before anaesthesia induction, but also highlighted that patients with a depressed mood had a much weaker response, probably the result of a heightened baseline (Kim et al., 2016). Again in humans, Rainville et al. (2006) showed that distinct patterns of HRV parameters can be used to differentiate between the emotions of fear, anger, happiness and sadness.

\subsubsection{Physiological components of equine emotion}

In animals the existence of such a variety of discrete emotions has yet to be determined and the distinction between positive and negative emotions (valence), together with a measure of intensity (arousal) is the current aim. As yet, no distinct physiological profiles in relation to specific emotional responses have been identified in the horse. As in most animal species, the generic 'stress' response has formed the basis of measuring how they 'feel' about management and training procedures (see Yarnell et al, 2013; König von Borstel et al., 2017). Indeed the terms acute / short-term stress and emotion are used inter-changeably. For example, visual startle tests (for example, using the sudden opening of an umbrella close to the horse) are considered as acute stressors, resulting in surprise, short term fear and avoidance responses, together with significant 
increases in HR and decreases in HRV (Villas-Boas et al., 2016). A positive correlation was found between behavioural signs of anxiety in isolated horses and increases in HR (Momozawa et al., 2007) and a task that was assessed as causing 'mental stress' to horses (walking backwards for three minutes) resulted in increased HR and decreased HRV (Rietmann et al., 2004). In all of the above examples changes in cardiovascular parameters will be associated with changes in physical activity. Startle responses include physical avoidance (Villas-Boas et al., 2016), isolation was associated with anxious behaviour (Momozawa et al., 2007) and walking backwards would have involved considerable physical effort (Rietmann et al., 2004). If any conclusions about equine emotion are to be drawn from measures of HR / HRV, the effect of physical activity must be taken into account. Jansen et al. (2009) used a mathematical model to differentiate between the physical and emotional components of changes in HR in response to sudden exposure to a novel object (the opening of an umbrella). Once the physical component had been extracted, the increases associated with the emotional component varied with individual horses and across the different trials within individuals (Jansen et al., 2009). From these findings it can be concluded that changes in HR provide information relating to the arousal component of emotion.

The increased arousal associated with positive anticipation resulted in a different cardiovascular response in horses than that recorded for sudden 'surprise' events. Peters et al. (2012) found significant increases in HR in horses when anticipating food, but no change in HRV. In humans, the anticipation of a potentially aversive scenario (anaesthesia preceding surgery) resulted in lowered HRV (Kim et al., 2016). In horses, a change in HRV during anticipatory behaviour could be indicative of the valence of that anticipation, decreasing when negative (or uncertain) outcomes were expected, unchanged when expectations were positive. Increases in $\mathrm{HR}$ were recorded in young race horses prior to entering an automated horse walker for the first time, a potentially anxiety-inducing anticipatory experience, but HRV was not recorded (Janczarek and Kędzierski, 2011). Smiet et al. (2014) included HRV in their evaluation of the effect of head and neck position during a set exercise test. They reported behavioural signs of negative anticipation in relation to specific head / neck positions and also differences in HRV (frequency domain). Significantly increased low frequency peaks and decreases in very low frequency were recorded with the head / neck 
positions that also resulted in behavioural signs of negative anticipation. Although the overall findings in relation to positive and negative anticipation are not wholly conclusive, there is some evidence that the changes in HRV could be linked to the valence of the anticipation. Further studies are now needed to test this hypothesis.

The surface temperature of the skin is influenced by the volume of blood distributed to it at any point in time which is under the control of the ANS. Infrared thermography (IRT) cameras can be used to measure this temperature as radiated heat (Stewart et al., 2007). Temperature changes of specific regions of the face have been used to measure emotional states in human infants (Mizukami et al.,1987), human adults (Engert et al., 2014; Khan et al., 2009), Rhesus monkeys (Nakayama et al., 2005) and Macaque monkeys (Kuraoka and Nakamura, 2011). Khan et al. (2009) demonstrated that whilst they could differentiate between intentional happy, sad and neutral faces, their accuracy reduced (from $83.3 \%$ to $67.2 \%$ ) when participants pretended to have happy, disgusted, surprised and angry expressions. This would suggest that the changes in facial temperature result from actual emotional experiences (causing changes in peripheral blood flow), as well as facial muscle activity associated with facial expression (see Ioannou et al., 2014).

In horses, as hair insulates the skin, the hairless periorbital region adjacent to the medial canthus has been used to detect thermal changes, with increases in temperature correlating with increases in arousal in several studies (Hall et al., 2011; Hall et al., 2014; McGreevy et al., 2012; Valera et al., 2012; Yarnell et al.,2013). To date these increases have generally been associated with negative valence, including correlation with behavioural signs of anxiety (Hall et al., 2014), response to sham clipping procedure (Yarnell et al., 2013) and discomfort (pain) associated with tight nosebands (McGreevy et al., 2012). In future it may be possible to identify more complex thermal facial patterns in the horse indicative of specific emotions. However, factors that affect surface temperature such as coat hair, colour, and moisture, as well the lateral positioning of the eyes in horses (making full facial patterns more difficult to capture) need addressing before this approach can be used reliably to detect underlying circulatory changes (König von Borstel et al., 2017; Pierard et al., 2015). 
Cortisol and its metabolites are the most widely used measures of the HPA axis response to aversive and arousing stimuli in horses (Möstl and Palme, 2002; Palme, 2012). Cortisol was initially thought to measure arousal levels regardless of valence, as cortisol increased with sexual stimulation of stallions, as well as with exposure to stressors or physical exertion (Colborn et al., 1991). However Pasing et al. (2013) failed to demonstrate a significant difference from baseline when semen was collected from experienced stallions. This may be explained in a number of different ways, including the possibility that the experienced stallions were habituated to the procedure and that it was no longer anxiety-provoking (more negatively valenced in less experienced animals); or that physical exertion was required to a greater extent in the study by Colborn et al. (1991) and this was the main cause of the increase in cortisol.

The sensitivity of cortisol to emotional changes remains unclear, and demonstration of a behavioural response to a stressor can occur without significant changes in cortisol levels (Honess and Marin, 2006; Rivera et al., 2002) questioning its sensitivity. In contrast when clipping horses, a potentially aversive procedure, salivary cortisol increased in all horses studied $(n=10)$ regardless of whether they demonstrated any behavioural signs of stress or not (Yarnell et al., 2013). This again highlights the challenges of assessing a horse's emotional state and the need for multiple measures. Behaviour that is influenced / controlled by past training and in some cases restraint, will not always reflect affective state. It has been suggested that reduced baseline cortisol levels are associated with longterm negative mental state and may be indicative of animals in a state of depression (Fureix et al., 2012). Changes in the natural circadian rhythm of cortisol also occur in response to long term negative mood states (Przkop et al., 1985) and such changes in baseline cortisol may be a useful indicator of the long term well-being of an animal.

Although cortisol measures may yield useful information regarding the affective state of an equine there are a number of limitations with this approach. These include the generally significant costs associated with the processing of biological samples, the many additional factors that contribute to both baseline measures and response rate, and the fact that the distinction between physical and mental stress (and subsequent emotional responses / mood states) has not been clarified with respect to HPA activity. It is likely however that HPA activity will provide at 
least a contribution to identifying emotional state, but as part of a series of measures rather than in isolation. For further discussion of physiological measures of stress in horses see König von Borstel et al. (2017) and Pierard et al. (2015).

\subsubsection{Physiological components warranting further investigation in relation to equine emotion}

Although HR, HRV and HPA activity are the most commonly used physiological measures of emotion in the horse to date, other parameters may yield further information regarding valence and the additional dimension of the associated motivation to approach or avoid (that relates to the emotion of anger/aggression or fear respectively: Mauss and Robinson, 2009). In humans cardiac activity has been linked to behavioural approach, whereas electrodermal responses were linked to behavioural inhibition (Gendolla and Krsken, 2001). Electrodermal responses have also been used in non-human primates (Amiez et al., 2003; Kuraoka and Nakamura, 2011; Laine et al., 2009) and rats (where underlying mood was found to influence this response: Guinjoan et al., 2004). Increases in core temperature have been associated with anxiety and stress responses in humans and other species (Oka et al., 2001) and preliminary findings suggest this measure may be of value in the horse (Hall et al., 2011). In humans, electroencephalography (EEG) is used to measure neuronal activity across the brain, with studies showing that asymmetry of EEG readings across the frontal lobe reflect the balance of approach motivation (left hemisphere) versus avoidance motivation (right hemisphere) (Mauss and Robinson, 2009). Although an ambulatory EEG for conscious horses has been developed (Cousillias, 2016), it still requires significant technological advances before similar studies could be undertaken in horses.

Other biomarkers that may provide additional information on equine emotion but are as yet largely untested/unvalidated in horses include oxytocin (urinary oxytocin has been suggested as a biomarker of positive emotion in dogs: Mitsui et al., 2011), serotonin (aggressive behaviours found to be associated with low serotonin levels within the brain: Koolhaas et al., 2010; inhibition of serotonin was found to induce pessimistic-like judgement bias in sheep: Doyle et al., 2011) and prolactin (which has been measured in horses and increases in response to exercise: Digiovanni et al., 2015; in response to stall confinement and 
transportation: King et al., 2009; and more recently in response to a surprise stimulus and social isolation: Bachman et al., 2017). McBride et al. (2017) reviewed the use of spontaneous blink rate (SBR) as a marker of dopamine transmission in rodents, with increased dopamine associated with an elevated SBR. There is evidence that SBR is also a behavioural marker of dopamine transmission in the horse (McBride et al., 2017). In humans the amplitude of eye blink, as measured by an electromyogram (EMG), is considered a good measure of emotional valence but less so of arousal (Mauss and Robinson, 2009). EMG has also been used to measure the activity of different muscles associated with facial behaviours indicative of emotions in people, for example those associated with furrowing of the eyebrows or raising the corners of the lips. Again these appear to be a better measure of valence than arousal (Mauss and Robinson, 2009). The identification of facial movements in terms of underlying muscle movements formed the basis of a system developed to enable an objective link to be made between facial expression and emotion in humans (Ekman and Friesen, 1980). A similar system has been developed to record the facial movements of the horse (EquiFACS: Wathan et al., 2015) and the use of EMG would provide an automated means of measuring subtle changes in equine facial expression and subsequently equine emotion.

\subsection{Behavioural components of emotion}

Emotions are often inferred through the changes in behaviours associated with them. These involve changes in motor action patterns such as those associated with fight, flight and avoidance responses, or approach and investigative behaviour or more subtle signs such as changes in body posture and facial expression, which may be accompanied by vocalisations. Behaviour is an outwardly visible sign of how an individual is experiencing stimuli, with spontaneous behavioural responses providing an indication of how they are being appraised (Paul et al., 2005). Behaviour as an indicator of emotion can be considered on two levels: while spontaneous behaviour represents the emotional response of an animal in the short term, longer term mental state can be assessed by evaluating patterns of behaviour and comparing these to the animal's natural behavioural repertoire (Benhajali et al., 2007). 


\subsubsection{Patterns of Behaviour, Behavioural Resilience and Emotional State}

Young (1999) described Behavioural Resilience as the degree to which a behaviour can resist being compressed in the time budget of an animal that has been forced to spend more of its time on another behaviour. Low resilience behaviours are less immediately important to the animal (for example, sleep, social interaction and exploratory behaviour) but compression can have long-term effects on health and well-being. High resilience behaviours typically have critical short term consequences for the animal (for example, feeding and drinking) and are maintained for as long as possible. Changes in patterns of behaviour may be manifest in a range of measurable ways, including change in relative frequencies of behaviours, decreased transitions between behaviours and increased durations of behaviours (Rutherford et al., 2006). The impact of external stimuli such as health issues and environmental conditions on the emotional state and resulting quality of life of an individual can be assessed through careful monitoring of behavioural changes (for example Mackintosh et al., 2011) and particularly behavioural resilience exhibited by individual animals (Young 1999). This has been done successfully in other species such as laying hens (Nicol et al., 2009).

Identifying and subsequently monitoring low resilience behaviours in the horse as a means of assessing general health and emotional well-being poses a number of challenges. The management of domestic horses frequently limits the extent to which they can participate in social behaviour (see Christensen et al., 2002; Hartmann et al., 2012) making this measure of emotional well-being problematic. Participation in social interaction is deemed rewarding to the horse (Van Dierendonck and Spruijt, 2012), as is mutual grooming behaviour that occurs between preferred associates (Feh and De Mazières, 1993; Kimura, 1998). Interactive behaviours could be classed as low resilience behaviours and in appropriate management conditions, could be a means of assessing emotional well-being in horses, although seasonal variation and other factors must be taken into consideration. It should be noted that the need for company or to be within view of other horses was prioritized over shelter and food (Schatzmann., 1998). Remaining within the 'herd' is a high resilience behaviour and important survival strategy in free-ranging horses. 
Patterns of sleep, in particular sleep deprivation, have been shown to relate to mental well-being in humans, with changes such as insomnia being associated with negative emotional states including stress, anxiety and depression (Waters et al., 1993). Sleep patterns in the horse were originally assessed by observation of body position and movement (or lack of movement) from which sleep type was implied (Pedersen et al., 2004). Accelerometers have been used to automatically detect lying behaviour in domestic horses (DuBois et al., 2015), but this still relies on implications based on body position. To enable more detailed analyses of the different phases of sleep in the horse, electroencephalography (EEG) has been used (Williams et al. 2008). Recent technological developments have resulted in more mobile EEG equipment that will facilitate the identification of 'normal' sleep patterns in the horse (Wöhr et al., 2016), enabling discrimination between neurologically based sleep disorders and those resulting from sleep deprivation or underlying health and/or emotional issues (Fuchs et al., 2016). Once it has been established what normal sleep patterns in a healthy, content horse should be, this will provide an additional means of assessing emotional well-being, mood state and subsequently quality of life. It should also be noted that environmental conditions and other factors that may cause sleep disturbances will likely affect emotional state and mood, making the evaluation of such aspects of management as housing and social grouping a priority (see Hartmann et al., 2012; Yarnell et al., 2015).

Environmental exploration has been used as a measure of how an animal feels. Such behaviour has been used to assess the impact of diet and weaning practice on the mental well-being of young horses (Nicol et al., 2005). Environmental exploration has been assessed using novel object or arena / open field tests (Wolff et al., 1997) and the positive relationship between interest in novel objects and housing / social contact found by Bulens et al. (2015) further emphasizes the need to consider more appropriate housing and social access for domestic horses. The level of emotional responsiveness has been used as a means of assessing temperament in horses, with responses to novel objects being found to correlate well with other measures (reactivity testing: McCall et al., 2006). Equine temperament is generally described in terms of the degree to which underlying emotion is displayed behaviourally (see Visser et al., 2001; Visser et al., 2003), with individual within-species differences forming the basis of the evaluation. Ijichi 
et al. (2014) found individual differences in the expression of pain, which was greatest in those classed as 'extrovert', regardless of the severity of damage.

Although the behavioural expression of emotion in the horse has value in terms of enabling an assessment of how they feel, the more expressive the animal is, the greater the risk to human safety. The selection of unexpressive individuals for roles involving inexperienced human handlers and riders may be advantageous for human safety, but is likely to compromise the well-being of the horses concerned. There is a need for measures that take into account individual differences in emotional reactivity (temperament), as well as those associated with age and gender (Janczarek and Kędzierski, 2011). With this proviso, general environmental interest is a valuable measure of underlying mood state (see Hall et al., 2008).

Play behaviour has been described as an activity that has no immediate specific function to the animal but one that is associated with pleasure (McFarland, 1999). The occurrence of play behaviour in young horses is well documented (including Crowell-Davis, 1983; Fagen and George, 1977; Feist, 1971; Tyler, 1972) and the developmental value of this behaviour is comparable with other species (Fagen, 1981). In free-ranging situations play behaviour occurs predominantly in subadult and non-breeding bachelor groups, and it is these animals that are generally the focus of studies of play behaviour in the horse (McDonnell and Poulin, 2002). The extent to which play behaviour may occur in adult domestic horses is an area for further investigation. In managed animals, less energy will be required to access food and water resources, the access to social interactions will vary but be controlled and generally there will be little environmental variation to motivate exploratory behaviour. The assumption that play behaviour signifies a positive mood state (McFarland, 1999), rather than an activity occurring through lack of other stimulation, requires confirmation in the domestic horse.

\subsubsection{Rebound behaviour}

Husbandry conditions have been demonstrated to have an effect on a horse's emotional state. This may result in modified behaviour and behaviour patterns, whereby behaviours whose expression has been limited (for whatever reason) occur more frequently when conditions change and arguably return to those that are more acceptable and better aligned with the equid's ethological requirements. 
This phenomenon of Post Inhibitory Rebound behaviour has been reported in horses post-confinement by both Freire et al. (2009) and Chaplin and Gretgrix (2010). The occurrence of Rebound behaviour has been shown to be subject to moderation through management activities such as the provision of social contact and stable size (Raabmagle and Ladewig 2006), but worryingly has also been shown to have serious impacts on horse welfare and human safety (e.g. Pessoa et al., 2016).

The emotional mediation in rebound behaviour was highlighted by McGreevy and Nicol (1998) in their investigation of the motivational consequences of short-term prevention of crib-biting. While the application of a cribbing collar for $24 \mathrm{~h}$ prevented crib biting in the majority of subjects $(6 / 8)$, removal of the collar resulted in a higher rate of cribbing due to post inhibitory rebound. It was proposed that rebound occurred due to an increase in internal motivation to cribbite when wearing the preventative collar. The inhibition of desired coping behaviour will have an emotional impact and compromise the horse's welfare (Freire et al., 2009; Nagy et al., 2009).

Post Inhibitory Rebound Effects are not limited to maintenance behaviours; Christensen et al. (2002) reported a rebound effect in social grooming and play behaviours in stallions after an extended period ( 9 months) of release postdeprivation. Rebound affects are also seen within the equitation context. Fenner et al. (2016) attributed significant increases compared to baseline, in yawning, swallowing and licking behaviours following removal of horse's nosebands to postinhibitory rebound. The occurrence of a 'dry mouth' during activation of the sympathetic nervous system (inhibiting salivation) and the subsequent return of salivation during sympathetic attenuation, is reflected in this behaviour. Similar occurrences are associated with performance anxiety in humans (Bourgeois, 1991).

In a social context, post-conflict affiliative behaviour has been shown to occur in horses living in a permanent social group, important for group stability and individual security (Cozzi et al., 2010). The occurrence of rebound behaviour is evidence of restrictive practice compromising equine behavioural needs. Emotional well-being is undoubtedly negatively impacted by such restrictions with the rebound behaviour probably associated with a rebound of positive emotion. 
Such scenarios offer a means of monitoring physiological and behavioural signs of positive emotion in the horse.

\subsubsection{Behavioural signs of spontaneous emotional response}

To assess the emotional impact of more short-term occurrences, immediate, often spontaneous, responses are recorded in situations where the emotional experience can be predicted. For example, isolating horses in novel environments and/or exposing them to unfamiliar objects or procedures, can be predicted to cause anxiety and fear responses (Forkman et al., 2007). Typical behavioural responses include increased vigilance behaviour, high head and tail position, snorting and locomotory responses (Forkman et al., 2007). As noted by Weeks (1996), the horse's ears are one indicator of emotional state. Horses' response to ear position in con-specifics has been demonstrated using 2-D images, with significantly more approach behaviour / interest shown to a picture of a horse's head with ears forwards than to one with ears back (Hall et al., 2012).

Facial expression has long been seen as the main way that emotion is communicated in humans and many animals (Darwin, 1998). Identification of features of facial expression in the horse as a means of determining emotional state has been the aim of a number of recent studies (e.g. Wathan et al., 2015), in particular as a means of recognising signs of pain (Dalla Costa et al., 2014; Gleerup et al., 2015; van Loon and van Dierendonck, 2015; Mullard et al., 2017). While features of facial expression associated with (induced) acute pain (flattened / asymmetrical ear position, withdrawn tense stare, dilated nostrils and muscle tension around the lips and chin) were suggested to be consistent signs of acute pain (Gleerup et al., 2015), in those studies involving less severe pain the need for further validation was identified. Both Van Loon and Van Dierendonck (2015) and Mullard et al. (2017) reported the need for further trials to test whether facial expression could be used to differentiate reliably those animals that were in pain. Alongside a veterinary composite pain scale and behavioural observations (of level of alertness and exploratory behaviour) the horse grimace scale, that combines different aspects of facial expression, did differentiate those individuals that had undergone a painful procedure (Dalla Costa et al., 2014). Some detailed analyses of more individual features of facial expression, such as wrinkles around the eye, have been proposed as being a potential means of evaluating the valence of 
emotional responses to procedures and possibly longer term mental state (Hintze et al., 2016). However, further research and validation of what such signs actually mean in terms of how horses feel is required before any reliable conclusions can be drawn.

Equine vocalisation also signifies emotional state and acts as a means of communicating this to others (Yeon, 2012). In free-ranging horses differences in squeal duration and frequency have been shown to differ in relation to dominance in stallions, communicating status and fighting ability and potentially arousal (Rubenstein and Hack, 1992). Differences between nickers and squeals in Przewalski's horses were attributed to differing motivational states and again, communicate affiliative or agonistic intention (Alberghina et al., 2016). In domestic horses, spectral differences in vocalisation in response to positive (feed expectation) and negative (mare-foal separation) occurrences were found (Pond et al., 2010). The evaluation of acoustic signals in situations where emotional experience can be predicted will provide further evidence of how horses feel. Yawning behaviour could also convey information regarding mental state as it is generally considered to be triggered by stress and emotional contexts (Fureix et al., 2011; Górecka-Bruzda et al., 2016), but findings to date are inconclusive.

Behaviour in preferred situations provides some evidence of signs of positive emotional state (e.g. lying behaviour with preferred bedding type; Pederson et al., 2004). Affiliative behaviour such as mutual grooming can be considered representative of positive emotional state (Feh and De Mazières, 1993) and consequently as evidence of emotional well-being. Ear position is undoubtedly a clear, if often transitory sign of affective state (Weeks, 1996), but other facial expressions indicative of positive emotion have yet to be conclusively identified in the horse. Vocalization offers a means of distinguishing between positive and negative emotions, but in the horse tends to relate to specific situations and may not be of generic use. Underlying mental state may be more clearly demonstrated in the way the horse appraises and responds to different situations; testing these cognitive aspects of emotion has revealed further evidence on which to assess how horses feel. 


\subsection{Cognitive components of emotion}

The impact of emotion on the acquisition of information and the resultant response has been studied in a number of species as discussed by Paul et al. (2005). Such studies in the horse have mainly focused on the impact of emotion on training, including the effect of fearfulness on learning (Christensen et al., 2012) and an evaluation of training methods aimed at reducing the response to frightening stimuli (Christensen et al., 2006). As identified by Paul et al. (2005) the cognitive components of emotion that should be considered in animals include how stimuli and situations are appraised (as positive, negative or neutral; fear invoking or pleasure inducing) and how emotional state may affect attention, memory and judgement.

\subsubsection{Appraisal of stimuli and situations}

A simple way of assessing whether stimuli are appraised as positive, negative or neutral is by monitoring whether their presentation results in approach or avoidance behaviour (Corr, 2013). Avoidance of a potentially threatening stimulus by the horse can involve active behaviours such as bolting or shying, or a passive refusal to approach. Both types of avoidance behaviours pose a risk to human handlers (McGreevy et al., 2014) and are often labelled as behavioural 'problems' (Hothersall and Casey, 2012), as well as signifying negative emotion in the horse. As a prey species, the horse is vigilant for signs of threat, responding with rapid avoidance behaviour potentiated by their relatively large amygdala (Takeuchi and Sugita, 2007) and extensive visual field (Murphy et al., 2009). This behaviour can be used to assess the impact of different environmental conditions on the mental well-beng of the horse. For example, a tracks system within horse pasture has been trialled in horses (Jackson, 2006). Although found to increase movement and positive social interactions in horses, this system also resulted in an increase in the occurrence of vigilance behaviour (standing alert), and a decrease in the time spent grazing (Winwright et al., 2015). Further assessment of preferred environments using choice tests is needed to establish the association between behavioural signs and underlying mood state. In terms of improving human safety, an important part of horse training involves changing the appraisal of stimuli and situations from negative to neutral, often by habituation or de-sensitization 
(Christensen et al., 2006). In addition, environments that are appraised positively will reduce potentially dangerous, fear-related responses.

The cerebral lateralization of emotion has been demonstrated in a number of species, including the horse, and may be used to assess the emotional valence attributed to stimuli. In general it has been shown that there is a right hemisphere cerebral dominance for negatively valenced stimuli (resulting in fear and aggression) and a left hemisphere dominance for positively valenced stimuli such as food or preferred associates (Leliveld et al., 2013). In the horse, asymmetry of visual exploration of negatively, positively or neutrally valenced stimuli was found, with a tendency for left eye exploration (right hemisphere) of negative and right eye exploration for neutral stimuli (De Boyer Des Roches et al., 2008). The tendency to handle horses predominantly from the left side undoubtedly increases the attention paid to stimuli on this side and would contribute to this finding. However, this would not account for the correlation found between a preference for investigating novel stimuli with the left eye and 'emotionality' scores in horses (Larose et al., 2006). The association between cerebral lateralisation of emotion and resultant behaviour offers some insight into how stimuli are appraised by horses but the impact of past experience on this must be considered before conclusions can be drawn.

The way in which humans are experienced by horses will determine their response to handling and training. Past experience has been demonstrated to influence the way in which humans are appraised by horses (Fureix et al., 2009) and positive (reward associated) interactions were found to result in lasting positive memories of humans (Sankey et al., 2010a). In the latter study, positive reward based training also enhanced learning and memorisation of the task concerned (Sankey et al., 2010a). Providing the horse with emotionally positive experiences will enhance the horse-human relationship and facilitate effective training.

\subsubsection{The impact of emotion on attention, memory and judgement}

Vigilance behaviour in animals occurs when they are paying attention to their surroundings and is associated with high levels of arousal (Paul et al., 2005). Although commonly linked to fear and anxiety in horses (Forkman et al., 2007), vigilance behaviour also occurs in positively valenced situations, when pleasurable outcomes are expected (such as food or preferred associates) (Paul et al., 2005). 
In humans, underlying mood state has been shown to affect what is paid attention to, with negative mood state resulting in more attention being paid to threatening / negatively valenced stimuli (Ioannou et al., 2004). In a prey species such as the horse, this propensity is likely to be accentuated. Such attention bias has been demonstrated in sheep, where chemically induced anxiety increased the attention paid to a potential threat (dog) (Lee at al., 2016). Selective attention is also affected by potential reward value. When training horses to remain immobile, Rochais et al. (2014) found that greater attention was paid to the trainer and learning performance was enhanced if the reinforcement used was food as opposed to wither scratching. Attention bias offers a means of assessing underlying positive and negative emotion in horses.

In the horse, the potential effect of fear and anxiety on cognition is particularly pertinent in relation to effective training (Christensen et al., 2006; Christensen et al., 2012). At least in novel environments fear appears to relate to lower learning ability in the horse (Christensen et al., 2012). Although events that are associated with emotional arousal, regardless of the valence of that arousal, tend to be remembered, memory consolidation is negatively affected by excessively high or low levels of arousal (Paul et al., 2005). In a review of the impact of 'stress' on cognition Mendl (1999) notes that performance may be enhanced by low-medium levels of 'stress' hormones and that memory can be state-dependent, i.e. memories formed when an animal is in a highly aroused state will be better recalled in the same state of arousal. This may in part explain one (anecdotal) feature of the horse's memory. Negative experiences resulting in pain or distress (physical or mental), appear to be remembered by the horse and affect future behavioural responses in similar scenarios. This is an adaptive cognitive feature for all animals, particularly prey species such as the horse, but may be problematic in their management and training.

Underlying mood / mental state has been found to affect judgements made about ambiguous stimuli by humans and other animals (Paul et al., 2005). Cognitive bias testing has been used to determine whether animals are in a positive (optimistic) or negative (pessimistic) frame of mind (Mendl et al., 2009), with environmental conditions being found to affect judgement bias in some species, including the rat (Brydges et al., 2011; Burman et al., 2009). A similar effect has been found in the horse, with increased optimism shown when pastured in herds 
following a period of being housed singly (Löckener et al., 2016). Judgement bias appears to become more positive when things have changed for the better. In a study by Freymond et al. (2014) this was demonstrated when the optimism of horses that had previously been trained using positive or negative reinforcement were compared. Positive reinforcement was used in the cognitive bias trials and those horses that had undergone negatively reinforced training prior to these trials showed more optimism (positive cognitive bias) than those that had been trained using positive reinforcement (Freymond et al., 2014). However, no conclusion can be drawn from these findings without further trials (incorporating negatively reinforced judgement bias trials) to ensure that it was a 'change for the better' in reinforcement that induced the positive cognitive bieas, as opposed to a change per se.

It has been suggested that the inclusion of positive reinforcement within training schedules may result in lower levels of emotional arousal and improved learning when compared with solely using negative reinforcement (Sankey at al., 2010b). When re-training rescued equids (during a rehabilitation programme), a positive reinforcement schedule was found to result in increased motivation to participate and increased exploratory behaviour than when a negative reinforcement schedule was used (Innes and McBride, 2008). The results of previous studies suggest that it is the change from a less preferred to a more preferred situation that lifts mood and improves optimism and initial findings suggest that moving towards a training system that includes positive reinforcement would improve the emotional wellbeing of at least some horses. However, the interaction between emotion, learning and performance in this species requires further investigation (McBride and Mills, 2012). Regardless, to improve the emotional well-being of all equines, the balance between positive and negative experiences needs to be tipped further towards the positive.

\section{Conclusion}

Despite the associated challenges, the need to devise a means of assessing the emotional component of equine behaviour is clear. In the short term, the identification of fear-inducing situations wil help to lessen human risk and enhance equine learning. In the longer term, the identification of emotional state will inform improvements in equine management and training, and consequently equine wellbeing. Based on the characterization of emotion in terms of arousal and valence, 
physiological measures such as HR provide a means of assessing arousal. Evidence of emotional valence is less conclusive, although HRV has been found to be affected by negatively valenced situations, but not by positive ones. Differentiation in terms of valence has also been found to be associated with specific types of vocalization. Changes in baseline cortisol level and the circadian rhythms thereof provide information about long term mood state, but as with all parameters, only as part of the overall profile of physiological and behavioural responses. Confounded by the fact that physiological and behavioural measures have yielded conflicting evidence and that behavioural expression is frequently subtle and potentially missed or misinterpreted, compiling such profiles is not straightforward. However, by combining evidence from cognitive tests, physiological profiles and identifying more subtle behavioural signs, as well as monitoring patterns of behaviour, we are getting closer to being able to determine, at least in part, the emotional state of the horse.

\section{Acknowledgements}

We would like to thank The Horse Trust for initiating an inter-disciplinary symposium to examine the "State of our Equine Nation" from a welfare perspective. This review is the first output from the Equine Behaviour Research Consortium (EBRC) which was founded there. 


\section{References}

Abelson, J. L., Weg, J. G., Nesse, R. M. \& Curtis, G. C. 1996. Neuroendocrine responses to laboratory panic: Cognitive intervention in the doxapram model. Psychoneuroendocrinology, 21, 375-390.

Alberghina, D., Caudullo, E., Chan, W.Y., Bandi, N., Panzera, M. 2016. Acoustic characteristics of courtship and agonistic vocalizations in Przewalskii's wild horse and in domestic horse. Applied Animal Behaviour Science 174: 70-75.

Amiez, C., Procyk, E., Honoré, J., Sequeira, H. and Joseph, J.-P. 2003. Reward anticipation, cognition, and electrodermal activity in the conditioned monkey. Experimental Brain Research, 149, 267-275.

Bachman, A., Thompson Jr. D.L., Walker, N.L. and Southerland, C.V. 2017. Hormonal and heart rate responses to a surprise stimulus and isolation stress in horses. Journal of Equine Veterinary Science 52, 61.

Beauchaine, T. 2001. Vagal tone, development, and Grays motivational theory: Toward an integrated model of autonomic nervous system functioning in psychopathology. Development and Psychopathology, 13, 183-214.

Benhajali, H., Hausberger, M., Richard-Yris, M.A. 2007. Behavioural repertoire: its expression according to environmental conditions. In: M. Hausberger, E. Søndergaard, W. Martin-Rosset (Eds.) Horse Behaviour and Welfare. EAAP publication No. 122. Wageningen Academic Publishers. Pp 123-138.

Boissy, A., Manteuffel, G., Jensen, M.B., Moe, R.O., Spruijt, B., Keeling, L.J., Winckler, C., Forkman, B., Dimitrov, I., Langbein, J., Bakken, M., Veissier, I. and Aubert, A. (2007) Assessment of positive emotions in animals to improve their welfare. Physiology and Behavior, 92(3) 375-397. Bourgeois, J.A. 1991. The management of performance anxiety with beta-adrenergic blocking agents. Jefferson Journal of Psychiatry 9: Article 5.

Boyd, L. and Keiper, R. (2005) Behavioural ecology of feral horses. In: D. Mills, S. McDonnell (eds.) The Domestic Horse: The Evolution, Development and Management of its Behaviour. Cambridge University Press, 55-82.

Brydges, N.M., Leach, M., Nicol, K., Wright, R., Bateson, M. 2011. Environmental enrichment induces optimistic cognitive bias in rats. Animal Behaviour 81: 169-175.

Bulens, A., Sterken, H., Van Beirendonck, S., Van Thielen, J., Driessen, B. 2015. The use of different objects during a novel object test in stabled horses. Journal of Veterinary Behavior 10: 54-58.

Burman, O.H.P., Parker, R.M.A., Paul, E.S., Mendl, M.T. 2009. Anxiety-induced cognitive bias in non-human animals. Physiology and Behavior 98: 345-350.

Cacioppo, J.T., Berntson, G.G.; Larsen, J.T.; Poehlmann, K.M. Ito, T.A. 2000. The psychophysiology of emotion. $2^{\text {nd }}$ Edition. In: R. Lewis and j.M. Haviland-Jones (Eds.) The Handbook of Emotion. New York: Guildford Press. 173-191.

Campbell, M. 2013. When does use become abuse in equestrian sport? Equine Veterinary Education 25: 489-492. 
Catipovic-Veselica, K., Amidzic, V., Durijancek, J., Kozmar, D., Sram, M., Glavas, B. et al. 1999. Association of heart rate and heart-rate variability with scores on the Emotion Profile Index in patients with acute coronary heart disease. Psychol Rep. 84: 433-442.

Cerutti, S., Mainardi, L.T. 1995. Spectral analysis of the heart rate variability signal. In: M. Malik (Ed.) Heart rate variability. Armonk, N.Y: Futura Publ. Comp., Inc.

Chaplin, S.J., and Gretgrix, L. 2010. Effect of housing conditions on activity and lying behaviour of horses. Animal. 4:5:792-795 doi:10.1017/S1751731109991704

Christensen, J.W., Ahrendt, L.P., Lintrup, R., Gaillard, C., Palme, R., Malmkvist, J. 2012. Does learning performance in horses relate to fearfulness, baseline stress hormone, and social rank? Applied Animal Behaviour Science 140: 44-52.

Christensen, J.W., Ladewig, J., Søndergaard, E., Malmkvist, J. 2002. Effects of individual versus group stabling on social behaviour in domestic stallions. Appl. Anim. Beh. Sci. 75: 233-247. Christensen, J.W., Rundgren, M., Olsson, K. 2006. Training methods for horses: habituation to a frightening stimulus. Equine Veterinary Journal 38: 439-443.

Christensen, J.W., Søndergaard, E., Thodberg, K., Halekoh, U. 2011. Effects of repeated regrouping on horse behaviour and injuries. Applied Animal Behaviour Science 133: 199-206.

Clark, D., and M. McGillivray. 2007. Measuring human well-being: Key findings and policy lesions. United Nations University, World Institute for Development Economics Research. Helsinki, Finland. Colborn, D.R., Thompson, D.L., Roth, T.L., Capehart, J.S., and White, K.L. 1991. Responses of cortisol and prolactin to sexual excitement and stress in stallions and geldings. Journal of Animal Science, 69, 2556-2562.

Colombetti, G. 2005. Appraising valence. Journal of Consciousness Studies 12: 103-126.

Cooper, J.J. and Albentosa, M.J. (2005) Behavioural adaptation in the domestic horse: potential role of apparently abnormal responses including stereotypic behaviour. Livestock Production Science, 92(2) 177-182.

Cooper, J.J. and Mason, G.J. (1998) The identification of abnormal behaviour and behavioural problems in stabled horses and their relationship to horse welfare: a comparative review. Equine Veterinary Journal, 30(S27) 5-9.

Corr, P.J. 2013. Approach and avoidance behaviour: Multiple systems and their interactions. Emotion Review 5: 285-290.

Cousillias, H., Oger, M., Rochais, C., Pettoello, C., Henry, S. and Hausberger, M. 2016. An ambulatory electroencephalography system for free moving horses: an innovative approach. 12th International Equitation Science Conference, 2016 Saumer, France. 143.

Cozzi, A., Sighieri, C., Gazzano, A., Nicol, C.J., Baragli, P. 2010. Post-conflict friendly reunion in a permanent group of horses (Equus caballus). Behavioural Processes 85: 185-190.

Crowell-Davis, S.L. 1983. The behavior of Welsh Pony foals and mares. PhD thesis, Cornell University, Ithaca, NY.

Dalla Costa, E., Minero, M., Lebelt, D., Stucke, D., Canali, E., Leach, M.C. 2014. Development of the Horse Grimace Scale (HGS) as a pain assessment tool in horses undergoing routine castration. PLoS ONE 9. E92281

Darwin, C. 1998. The expression of the emotions in man and animals ( $3^{\text {rd }}$ Ed.). Oxford University Press. 
De Boyer Des Roches, A., Richard-Yris, M.-A., Henry, S., Ezzaouïa, M., Hausberger, M. 2008. Laterality and emotions: Visual laterality in the domestic horse (Equus caballus) differs with objects' emotional value. Physiology and Behavior 94: 487-490.

de Waal FBM. 2011. What is an animal emotion? In: Miller MB, Kingstone A ed. Year in Cognitive Neuroscience. Oxford, Blackwell Science Publ. Pp. 191-206.

Derksen, F.J., Clayton, H.M. 2007. Is equitation science important to veterinarians? The Veterinary Journal. 174. 452-453.

Digiovanni, L.C.; Thompson, D.L.; Valencia, N.A.; Oberhaus, E.L. 2015. 142 Factors affecting basal and post-exercise prolactin secretion in horses. Journal of Equine Veterinary Science 35, 444.

Doyle, R.E., Hinch, G.N., Fisher, A.D., Boissy, A., Lee, C. 2011. Administration of serotonin inhibitor p-Chlorophenylalanine induces pessimistic-like judgement bias in sheep.

Psychoneuroendocrinology 36: 279-288.

DuBois, C., Zakrajsek, E., Haley, D.B. and Merkies, K. 2015. Validation of triaxial accelerometers to measure lying behaviour of adult domestic horses. Animal 9: 110-114..

Ekman, P., Friesen, W.V. 1980. Facial signs of emotional experience. Journal of Personality and Social Psychology 39: 1125-1134.

Ekman, P., Levenson, R.W., Friesen, W.V. 1983. Autonomic nervous system activity distinguishes among emotions. Science. 221, 1208-1210.

Elliot, A.J., Eder, A.B., Harman-Jones, E. 2013. Approach-avoidance motivation and emotion: Convergence and divergence. Emotion Review 5: 308-311.

Engert, V., Merla, A., Grant, J. A., Cardone, D., Tusche, A. and Singer, T. 2014. Exploring the Use of Thermal Infrared Imaging in Human Stress Research. (Research Article). PLoS ONE, 9, e90782. Fagen, R. 1981. Animal Play Behavior. Oxford University Press, New York.

Fagen, R.M. and George, T.K. 1977. Play behavior and exercise in young ponies (Equus caballus L.) Behav. Ecol. Sociobiol. 2 267-269.

Fédération Equestre Internationale. 2009. FEI Rules for Dressage Events. 23rd edition. Fédération Equestre Internationale. Lausanne, Switzerland.

Feh C (2005) Relationships and communication in socially natural horse herds. In: Mills D, McDonnell S (eds) The domestic horse: the evolution, development and management of its behaviour. Cambridge University Press, Cambridge, pp 83-93

Feh, C. and De Mazières, J. 1993. Grooming at a preferred site reduces heart rate in horses. Animal Behaviour 46: 1191-1194.

Feist, J.D. 1971. Behavior of feral horses in the Pryor Mountain Wild Horse Range. Master's thesis. University of Michigan, Ann Arbor.

Fell, D., Derbyshire, D. R., Maile, C. J., Larsson, I. M., Ellis, R., Achola, K. J. \& Smith, G. 1985.

Measurement of plasma catecholamine concentrations. An assessment of anxiety. British journal of anaesthesia, 57, 770.

Fenner, K., Yoon, S., White, P., Starling, M., McGreevy, P., 2016. The Effect of Noseband Tightening on Horses' Behavior, Eye Temperature, and Cardiac Responses. PLoS ONE. 11, e0154179. doi:10.1371/journal.pone.0154179

Figueroa, M. 2007. The effects of Tai Chi Chuan and Chi Kung on autonomic modulation. In: Demeersman, R. (Ed.). ProQuest Dissertations Publishing. Pp 1-94. 
Fleming, P.A., Paislet, C.L., Barnes, A.L., Wemelsfelder, F. 2013. Application of Qualitative Behavioural Assessment to horses during an endurance ride. Applied Animal Behaviour Science 144, 80-88.

Forkman, B., Boissy, A., Meunier-Salaün, M.-C., Canali, E., Jones, R.B. 2007. A critical review of fear tests used on cattle, pigs, sheep, poultry and horses. Physiology and Behavior 92: 340-374. Fraser, D. 2008. Understanding animal welfare: the science in its cultural context. Kirkwood JK, Hubrecht RC ed. Oxford, Wiley-Blackwell.

Freire, R., Buckley, P., Cooper, J.J. 2009. Effects of different forms of exercise on post inhibitory rebound and unwanted behaviour in stabled horses. Equine Veterinary Journal 41, 487-492, doi: $10.2746 / 095777309 \times 383883$

Freymond, S.B., Briefer, E.F., Zollinger, A., Gindrat-von Allmen, Y., Wyss, C., Bachmann, I. 2014. Behaviour of horses in a judgement bias test associated with positive or negative reinforcement. Applied Animal Behaviour Science 158: 34-45.

Fuchs, C. Kiefner, C., Reese, S., Erhard, M., Wöhr, A-C. 2016. Narcolepsy: Do adult horses really suffer from a neurological disorder or rather from a recumbent sleep deprivation / rapid eye movement (REM) sleep deficiency? Equine Veterinary Journal 48. Supplement 50 (Abstract):9. Fureix, C., Beaulieu, C., Argaud, S., Rochais, C., Quinton, M., Henry, S., Hausberger, M. and Mason, G. (2015) Investigating anhedonia in a non-conventional species: Do some riding horses (Equus caballus) display symptoms of depression? Applied Animal Behaviour Science, 162: 26-36. Fureix, C., Górecka-Bruzda, A., Gautier, E., Hausberger, M. 2011. Cooccurrence of yawning as stereotypic behaviour in horses (Equus caballus). ISRN Zoology . Article ID 271209, 10 pages. Fureix, C., Jego, P., Henry, S., Lansade, L. and Hausberger, M. 2012. Towards an Ethological Animal Model of Depression? A Study on Horses (Towards an Ethological Animal Model of Depression). PLoS ONE, 7, e39280.

Fureix, C., Jego, P., Sankey, C., Hausberger, M. 2009. How horses (Equus caballus) see the world: humans as significant "objects". Animal Cognition 12: 643-654.

Garland EL, Fredrickson B, Kring AM, Johnson DP, Meyer PS, Penn DL 2010. Upward spirals of positive emotions counter downward spirals of negativity: Insights from the broaden-and-build theory and affective neuroscience on the treatment of emotion dysfunctions and deficits in psychopathology. Clinical Psychology Review 30(7): 849-864.

Gendolla, G. H. E. and Krsken, J. A. N. 2001. The joint impact of mood state and task difficulty on cardiovascular and electrodermal reactivity in active coping. Psychophysiology, 38, 548-556. Gleerup, K.B., Forkman, B., Lindegaard, C., Anderson, P.H. 2015. An equine pain face. Veterinary Anaesthesia and Analgesia 42: 103-114.

Goodwin, D. (1999) The importance of ethology in understanding the behaviour of the horse. Equine veterinary journal. Supplement, 28(28) 15-19.

Górecka-Bruzda, A., Fureix, C., Ouvrard, A., Bourjade, M., Hausberger, M. 2016. Investigating determinants of yawning in the domestic (Equus caballus) and Przewalski (Equus ferus przewalskii) horses. Sci Nat 103: 72. DOI: 10.1007/s00114-016-1395-7

Guinjoan S. M., Yannielli, P. C., Lococco, J., Siri, N. and Cardinali, D. P. 2004. Electrodermal Response in Nonglabrous Skin of Freely Moving Rats: Mediation by the Sympathetic Nervous System and Evaluation in an Animal Model of Depression. Neuropsychobiology, 33, 147-154. 
Hall, C., Burton, K., Maycock, E. and Wragg, E. 2011. A preliminary study into the use of infrared thermography as a means of assessing the horse's response to different training methods. Hall, C.A., Goodwin, D., Heleski, C., Randle, H., Waran, N. 2008. Is there evidence of learned helplessness in horses? Journal of Applied Animal Welfare Science 11: 249-266.

Hall, C., Kay, R. and Yarnell, K. 2014. Assessing ridden horse behavior: Professional judgment and physiological measures. Journal of Veterinary Behavior: Clinical Applications and Research, 9, 2229.

Hall, C., Rigg, V., Truswell, M., Owen, H. 2012. Picture recognition of con-specifics and facial expression in the horse (Equus caballus). Proceedings: International Equine Science Meeting, Regensburg, Germany. March. P 55.

Hartmann, E., Søndergaard, E., Keeling, L.J. 2012. Keeping horses in groups: A review. Applied Animal Behaviour Science 136: 77-87.

Hintz, S., Smith, S., Patt, A., Bachmann, I., Würbel, H. 2016. Are eyes a mirror of the soul? What eye wrinkles reveal about a horse's emotional state. PLOS ONE

DOI: $10.1371 /$ journal.pone.0164017

Honess, P. E. and Marin, C. M. 2006. Behavioural and physiological aspects of stress and aggression in nonhuman primates. Neuroscience and Biobehavioral Reviews, 30, 390-412. Hothersall, B., Casey, R. 2012. Undesired behaviour in horses: A review of their development, prevention, management and association with welfare. Equine Veterinary Education 24: 479-485. Ijichi, C., Collins, L.M., Elwood, R.W. 2014. Pain expression is linked to personality in horses. Applied Animal Behaviour Science 152: 38-43.

Innes L, McBride, S. 2008. Negative versus positive reinforcement: An evaluation of training strategies for rehabilitated horses. Applied Animal Behaviour Science 112(3-4): 357-368. Ioannou, M.C., Mogg, K., Bradley, B.P. 2004. Vigilance for threat: effects of anxiety and defensiveness. Pers. Indiv. Diff. 36: 1879-1891.

Ioannou, S., Gallese, V., Merla, A. 2014. Thermal infrared imaging in psychophysiology: Potentialities and limits. Psychophysiology 51: 951-963.

Jackson, J. 2006. Paddock Paradise. Star Ridge Publishing, USA.

Janczarek, I., Kędzierski, W. 2011. Emotional response to novelty in young race horses. Journal of Equine Veterinary Science 31: 549-554.

Jansen, F., Van der Krogt, J., Van Loon, K., Avezzù, V., Guarino, M., Quanten, S,. Berckmans, D. 2009. Online detection of an emotional response of a horse during physical activity. The Veterinary Journal 181: 38-42.

Jeon, D., Kim, S., Chetana, M., Jo, D., Ruley, H.E., Lin, S-Y., Rabah, D., Kinet, J-P., Shin, H-S. 2010. Observational fear learning involves affective pain system and $\mathrm{Ca}_{v} 1.2 \mathrm{Ca}^{2+}$ channels in ACC. Nat Neurosci 13: 482-488.

Khan, M., Ward, R. and Ingleby, M. 2009. Classifying pretended and evoked facial expressions of positive and negative affective states using infrared measurement of skin temperature. ACM Transactions on Applied Perception (TAP), 6, 1-22.

Kim, E.-H., Park, J.-H., Lee, S. M., Gwak, M.-S., Kim, G.-S. and Kim, M.-H. 2016. Preoperative depressed mood and perioperative heart rate variability in patients with hepatic cancer. Journal of Clinical Anaesthesia, 35, 332-338. 
Kimura, R. 1998. Mutual grooming and preferred associate relationships in a band of free-ranging horses. Applied Animal Behaviour Science 59: 265-276.

King, S.S., Maiero, A., Marlo, T., Roser, J.F., Webel., S.K. and Jones, K.L. 2009. The Effect of Omega-3 Fatty Acid Supplementation on Cortisol and Prolactin Concentrations in Response to Common Stressors in Horses. Journal of Equine Veterinary Science 29 (5), 421-422.

König von Borstel, U., Visser, K., Hall, C. 2017. Indicators of stress in equitation. Applied Animal Behaviour Science. 190, 43-56.

Koolhaas, J. M., de Boer, S. F., Coppens, C. M. \& Buwalda, B. 2010. Neuroendocrinology of coping styles: Towards understanding the biology of individual variation. Frontiers in Neuroendocrinology, 31, 307-321.

Kreibig, S. D., Wilhelm, F. H., Roth, W. T. and Gross, J. J. 2007. Cardiovascular, electrodermal, and respiratory response patterns to fear- and sadness-inducing films. Psychophysiology, 44, 787806.

Kuraoka, K. and Nakamura, K. 2011. The use of nasal skin temperature measurements in studying emotion in macaque monkeys. Physiology \& Behavior, 102, 347-355.

Laine, C. M., Spitler, K. M., Mosher, C. P. and Gothard, K. M. 2009. Behavioral triggers of skin conductance responses and their neural correlates in the primate amygdala. Journal of Neurophysiology, 101, 1749.

Larose, C., Richard-Yris, M.-A., Hausberger, M. 2006. Laterality of horses associated with emotionality in novel situations. Laterality 11: 355-367.

Lee, C., Verbeek, E., Doyle, R., Bateson, M. 2016. Attention bias to threat indicates anxiety differences in sheep. Biology Letters 12: 20150977.

Leliveld, L.M.C., Langbein, J., Puppe, B. 2013. The emergence of emotional lateralization: Evidence in non-human vertebrates and implications for farm animals. Applied Animal Behaviour Science 145: 1-14.

Levenson, R.W. 1992. Autonomic nervous system differences among emotions. Psychological Science 3: 23-27.

Löckener, S., Reese, S., Erhard, M., Wöhr, A.-C. 2016. Pasturing in herds after housing in horseboxes induces a positive cognitive bias in horses. Journal of Veterinary Behavior 11: 50-55. Mackintosh, A.J.J., Alados, C.L, Huffman, M.A. 2011. Fractal analysis of behaviour in a wild primate: behavioural complexity in health and disease. J. Royal Society interface 8, 1497-1509. Mauss, I. and Robinson, M. 2009. Measures of emotion: A review. Cognition \& Emotion, 23, 209237.

McBride, S.D., Mills, D.S. 2012. Psychological factors affecting equine performance. BMC Veterinary Research 8: 180

McBride, S. D., Parker, M. O., Roberts, K. and Hemmings, A. 2017. Applied neurophysiology of the horse; implications for training, husbandry and welfare. Applied Animal Behaviour Science, 190, 90-101.

McCall, C.A., Hall, S., McElhenney, W.H., Cummins, K.A. 2006. Evaluation and comparison of four methods of ranking horses based on reactivity. Applied Animal Behaviour Science 96: 115-127. 
McCraty, R., Atkinson, M., Tiller, W. A., Rein, G. \& Watkins, A. D. 1995. The effects of emotions on short-term power spectrum analysis of heart rate variability. The American Journal of Cardiology, 76, 1089-1093.

McCraty, R., Barrios-Choplin, B., Rozman, D., Atkinson, M. and Watkins, A. 1998. The impact of a new emotional self-management program on stress, emotions, heart rate variability, DHEA and cortisol. Integrative Physiological and Behavioral Science, 33, 151-170.

McDonnell, S.M. and Poulin, A. 2002. Equid play ethogram. Applied Animal Behaviour Science 78: 263-290.

McFarland, D. 1999. Animal behaviour: Psychobiology, Ethology and Evolution. (3 ${ }^{\text {rd }}$ Edition) Addison Wesley Longman Ltd., Harlow, Essex.

McGreevy, P.D., Henshall, C., Starling, M.J., McLean, A.N., Boakes, R.A. 2014. The importance of safety signals in animal handling and training. Journal of Veterinary Behavior 9: 382-387.

McGreevy, P.D., Nicol, C.J. 1998. The effect of short term prevention on the subsequent rate of crib-biting in Thoroughbred horses. Equine Veterinary Journal. 30(s27). DOI: 10.1111/j.20423306.1998.tb05142.

McGreevy, P., Warren-Smith, A. and Guisard, Y. 2012. The effect of double bridles and jawclamping crank nosebands on temperature of eyes and facial skin of horses. Journal of Veterinary Behavior: Clinical Applications and Research, 7, 142-148.

Mendl, M. 1999. Performing under pressure: stress and cognitive function. Applied Animal Behaviour Science 65: 221-244.

Mendl, M., Burman, O.H.P., Parker, R.M.A., Paul, E.S. 2009. Cognitive bias as an indicator of animal emotion and welfare: Emerging evidence and underlying mechanisms. Applied Animal Behaviour Science 118, 161-181.

Mendl, M., Burman, O.H.P. and Paul, E.S. (2010) An integrative and functional framework for the study of animal emotion and mood. Proceedings of the Royal Society B: Biological Sciences, 277(1696), 2895-2904.

Minero, M., Tosi, M.V., Canali, E., Wemelsfelder, F. 2009. Quantitative and qualitative assessment of the response of foals to the presence of an unfamiliar human. Applied Animal Behaviour Science 116: 74-81.

Minero, M., Dalla Costa, E., Dai, F., Murray, L.A.M., Canali, E., Wemelsfelder, F. 2016. Use of Qualitative Behaviour Assessment as an indicator of welfare in donkeys. Applied Animal Behaviour Science 174: 147-157.

Mitsui, S. Yamamoto M, Nagasawa M, Mogi K, Kikusui T, Ohtani N, Ohta M. 2011. Urinary oxytocin as a noninvasive biomarker of positive emotion in dogs. Hormones and Behavior 60, 239-243. Mizukami, K., Kobayashi, N., Iwata, H., Ishii, T. 1987. Telethermography in infant's emotional behavioural research. Lancet, 11, 38-39.

Momozawa, Y., Terada, M., Sato, F., Kikusui, T., Takeuchi, Y., Kusonose, R., Mori, Y. 2007. Assessing equine anxiety-related parameters using an isolation test in combination with a questionnaire survey. J. Vet. Med. Sci. 69: 945-950.

Möstl, E. and Palme, R. 2002. Hormones as indicators of stress. Domestic Animal Endocrinology, 23, 67-74. 
Mullard, J., Berger, J.M., Ellis, A.D., Dyson, S. 2017. Development of an ethogram to describe facial expressions in ridden horses (FEReq). Journal of Veterinary Behavior 18: 7-12.

Murphy, J., Hall, C.A., Arkins, S. 2009. What horses and humans see: A comparative review. International Journal of Zoology (available online).

Nagy, K., Bodo, G., Bardos, G., Andrea Harnos, A., and Kabai, P. 2009. The effect of a feeding stress-test on the behaviour and heart rate variability of control and crib-biting horses (with or without inhibition). Applied Animal Behaviour Science, 121: 140-147.

Nakayama, K., Goto, S., Kuraoka, K. and Nakamura, K. 2005. Decrease in nasal temperature of rhesus monkeys (Macaca mulatta) in negative emotional state. Physiology \& Behavior, 84, 783790.

Napolitano, F., De Rosa, G., Braghieri, A., Grasso, F., Bordi, A. Wemelsfelder, F. 2008. The qualitative assessment of responsiveness to environmental challenge in horses and ponies. Applied Animal Behaviour Science 109, 342-354.

Nicol, C.J., Badnell-Waters, A.J., Bice, R., Kelland, A., Wilson, A.D. and Harris, P.A. 2005. The effects of diet and weaning method on the behaviour of young horses. Applied Animal Behaviour Science 95: 205-221.

Nicol, C.J., Caplen, G., Edgar, J., Browne, W.J. 2009. Associations between welfare indicators and environmental choice in laying hens. Animal Behaviour 78: 413-424.

Oka, T., Oka, K., Hori, T. 2001. Mechanisms and mediators of psychological stress-induced rise in core temperature. Psychosomatic Medicine 63: 476-486.

Palme, R. 2012. Monitoring stress hormone metabolites as a useful, non-invasive tool for welfare assessment in farm animals. Animal Welfare, 21, 331-337.

Panksepp, J. 2005. Affective consciousness: Core emotional feelings in animals and humans. Consciousness and Cognition 14(1): 30-80.

Pasing, S., Von Lewinski, M., Wulf, M., Erber, R. and Aurich, C. 2013. Influence of semen collection on salivary cortisol release, heart rate, and heart rate variability in stallions. Theriogenology, 80 , 256-261.

Paul, E.S., Harding, E.J. and Mendl, M. (2005) Measuring emotional processes in animals: The utility of a cognitive approach. Neuroscience and Biobehavioral Reviews, 29(3) 469-491.

Pedersen, G.R., Søndergaard, E., Ladewig, J. 2004. The influence of bedding on the time horses spend recumbent. Journal of Equine Veterinary Science 24: 153-158.

Peeters, M., Closson, C., Beckers, J-F., Vandenheede, M. 2013. Rider and horse salivary cortisol levels during competition and impact on performance. Journal of Equine Veterinary Science 33: 155-160.

Pessoa, G.O., Trigo, P., Mesquita Neto, F.D., Lacreta Junior, A.C.C., Sousa, T.M., Muniz, J.A., Moura, R.S. 2016. Comparative well-being of horses kept under total or partial confinement prior to employment for mounted patrols. Appl. Anim. Behav. Sci. 184. 51-58.

Peters, s.M., Bleijenberg, E.H., van Dierendonck, M.C., van der Harst, J.E., Spruijt, B.M. 2012. Characterization of anticipatory behaviour in domesticated horses (Equus caballus). Applied Animal Behaviour Science 138: 60-69. 
Pierard, M., Hall, C., König von Borstel, U., Averis, A., Hawson, L., McLean, A., Nevison, C., Visser, K., McGreevy, P. 2015. Evolving protocols for research in equitation science. Journal of Veterinary Behavior 10: 255-266.

Pond, R.L., Darre, M.J., Scheifele, P.M., Browning, D.G. 2010. Characterization of equine vocalization. Journal of Veterinary Behavior 5: 7-12.

Porges, S. W., Doussard-Roosevelt, J. A., Portales, A. L. and Greenspan, S. I. 1996. Infant regulation of the vagal "brake" predicts child behavior problems: a psychobiological model of social behavior. Developmental psychobiology, 29, 697.

Przkop, F., Stupnicka, E., Wolinska-Witort, E., Mateusiak, K., Sadowski, B. Domanski, E. 1985.

Changes in circadian rhythm and suppression of the plasma cortisol level after prolonged stress in the sheep. Acta Endocrinologica, 110, 540-545.

Raabmagle, P., and Ladewig, J. 2006. Lying Behavior in Horses in Relation to Box Size. Journal of Equine Veterinary Science. 26(1): 10-17

Rainville, P., Bechara, A., Naqvi, N. and Damasio, A. R. 2006. Basic emotions are associated with distinct patterns of cardiorespiratory activity. International Journal of Psychophysiology, 61, 5-18. Randle, H., Steenbergen, M., Roberts, K., Hemmings, A. 2017. The use of technology in equitation science: A panacea or abductive science? Applied Animal Behaviour Science 190: 57-73. Rietmann, T.R., Stuart, A.E.A., Bernasconi, P., Stauffacher, M., Auer, J.A., Weishaupt, M.A. 2004. Assessment of mental stress in warmblood horses: heart rate variability in comparison to heart rate and selected behavioural parameters. Applied Animal Behaviour Science 88: 121-136.

Rivera, E., Benjamin, S., Nielsen, B., Shelle, J. and Zanella, A. J. 2002. Behavioral and physiological responses of horses to initial training: the comparison between pastured versus stalled horses. Applied Animal Behaviour Science, 78, 235-252.

Rochais, C., Henry, S., Fureix, C. and Hausberger, M. (2016) Investigating attentional processes in depressive-like domestic horses (Equus caballus). Behavioural Processes, 124 93-96.

Rochais, C., Henry, S., Sankey, C., Nassur, F., Górecka-Bruzda, A., Hausberger, M. 2014. Visual attention, an indicator of human-animal relationships? A study of domestic horses (Equus caballus). Frontiers in Psychology 5, DOI: 10.3389/fpsyg.2014.00108

Rubenstein, D.L., Hack, M.A. 1992. Horse signals: the sounds and scents of fury. Evolutionary Ecology 6: 254-260.

Rutherford, K.M.D., Haskell, M.J., Glasbey, C, Lawrence, A.B. 2006. The responses of growing pigs to a chronic-intermittence stress treatment. Physiology and Behavior 89, 670-680.

Sankey, C., Richard-Yris, M.A., Henry, S., Fureix, C., Nassur, F., Hausberger, M. 2010b.

Reinforcement as a mediator of the perception of humans by horses (Equus caballus). Animal Cognition 13: 753-764.

Sankey, C., Richard-Yris, M.-A., Leroy, H., Henry, S., Hausberger, M. 2010a. Positive interactions lead to lasting positive memories in horses, Equus caballus. Animal Behaviour 79:869-875.

Schatzmann, U. 1998. Winter pasturing of sport horses in Switzerland - an experimental study. Equine Veterinary Journal Supplement 27: Equine Clinical Behaviour: 54.

Schmidt, A., Aurich, J., Mőstl, E., Müller, J., Aurich, C. 2010. Changes in cortisol release and heart rate and heart rate variability during the initial training of 3 -year-old sport horses. Hormones and Behavior. 58. 628-636. 
Silver, J.R., Lloyd Parry, J.M. 1991. Hazards of horse-riding as a popular sport. British Journal of Sports Medicine, 25(2), 105-110.Sleigh, J. W., Henderson, J.D. 1995. Heart-rate-variability and preoperative anxiety. Acta Anaesthesia Scandiavica, 39, 1059-106

Smiet, E., Van Dierendonck, M.C., Sleutjens, J., Menheere, P.P.C.A., van Breda, E., de Boer, D., Back, W., Wijnberg, I.D., van der Kolk, J.H. 2014. Effect of different head and neck positions on behaviour, heart rate variability and cortisol levels in lunged Royal Dutch Sport horses. The Veterinary Journal 202: 26-32.

Špinka, M. 2012. Social dimension of emotion and its implication for animal welfare. Applied Animal Behaviour Science 138, 170-181.

Stewart, M., Webster, J. R., Verkerk, G. A., Schaeffer, A. L., Colyn, J. J. and Stafford, K. J. 2007. Non-invasive measurement of stress in dairy cows using infrared thermography. Physiology \& Behavior, 92, 520-525.

Stockman, C. A., Collins, T., Barnes, A. L., Miller, D., Wickham, S. L., Beatty, D. T D. Blache, T.D., Wemelsfelder, F., Fleming, P. A. 2011. Qualitative behavioural assessment and quantitative physiological measurement of cattle naïve and habituated to road transport. Animal Production Science 51: 240-249.

Stratton R, Waran N, Beausoleil N, Stafford K, Worth G, Munn R, Stewart M 2010. Non-invasive assessment of positive emotions in horses using behavioural and physiological indicators

[Abstract]. In: Hartmann E, Zetterqvist Blokhuis M, Fransson C, Dalin G ed. Conference Proceedings, ISES Sweden 2010, 6th International Equitation Science Conference, Uppsala 31 July - 2 August 2010, Horse welfare and human safety: Importance of learning, training and education. Uppsala, Sweden. Pp. 42-43.

Takeuchi, T., Sugita, S. 2007. Histological atlas and morphological features by Nissl staining in the amygdaloid complex of the horse, cow and pig. Journal of Equine Veterinary Science 18: 13-25.

Tyler, S.J. 1972. Behaviour and social organization of the New Forest ponies. Animal behaviour Monograph 5.

Valera, M., Bartolomé, E., Sánchez, M. J., Molina, A., Cook, N. \& Schaeffer, A. 2012. Changes in eye temperature and stress assessment in horses during show jumping competitions. Journal of Equine Veterinary Science, 32, 827-830.

Van Dierendonck, M.C., Spruijt, B.M. 2012. Coping in groups of domestic horses - Review from a social and neurobiological perspective. Applied Animal Behaviour Science 138: 194-202.

Van Loon, J.P.A.M., Van Dierendonck, M.C. 2015. Monitoring acute visceral pain with the Equine Utrecht University Scale for Composite Pain Assessment (EQUUS-COMPASS) and the Equine Utrecht University Scale for Facial Assessment of Pain (EQUUS-FAP): A scale-construction study. The Veterinary Journal 206: 356-364.

Villas-Boas, J.D., Dias, D.P.M., Trig, P.i., dos Santos Almeida, N.A., de Almeida, F.Q., de Medeiros, M.A. 2016. Behavioural, endocrine and cardiac autonomic responses to a model of startle in horses. Applied Animal Behaviour Science 174: 76-82.

Visser, E.K., van Reenen, C.G., Hopster, H., Schilder, M.B.H., Knaap, J.H., Barneveld, A., Blokhuis, H.J. 2001. Quantifying aspects of young horses' temperament: consistency of behavioural variables. Applied Animal Behaviour Science 74: 241-258. 
Visser, E.K., van Reenen, C.G., Rundgren, M., Zetterqvist, M., Morgan, K., Blokhuis, H.J. 2003. Responses of horses in behavioural tests correlate with temperament assessed by riders. Equine Veterinary Journal 35: 176-183.

Waters, W.F., Adams, Jr., S.G., Binks, P., Varnado, P. 1993. Attention, stress and negative emotion in persistent sleep-onset and sleep maintenance insomnia. Sleep 16: 128-136.

Wathan, J., Burrows, A.M., Waller, B.M., McComb, K. 2015. EquiFACS: The equine facial action coding system. PLOS ONE DOI: 10.1371/journal.pone.0131738

Weeks, J. 1996. Equine agitation behaviors. Equine Practice 18:23-24.

Weiten W 1992. Psychology: themes and variations. 2nd ed. Pacific Grove, California, Brooks/Cole Publishing Company.

Wemelsfelder, F., Hunter, E.A., Mendl, M.T., Lawrence, A.B., 2000. The spontaneous qualitative assessment of behavioural expressions in pigs: first explorations of a novel methodology for integrative animal welfare measurement. Applied Animal Behaviour Science. 67, 193-215. Wemelsfelder, F., Hunter, T.E.A., Mendl, M.T., Lawrence, A.B., 2001. Assessing the 'whole animal': a free choice profiling approach. Animal Behaviour. 62, 209-220.

Wemelsfelder, F. and Mullan, S. 2014. Applying Ethological and Health Indicators to Practical Animal Welfare Assessment. Technical Review, Office International des Epizooties, 33, 111-20. Williams, D.C., Aleman, M., Holliday, T.A., Fletcher, D.J., Tharp, B., Kass, P.H., Steffey, E.P., LeCouteur, R.A. 2008. Qualitative and quantitative characteristics of the electroencephalogram in normal horses during spontaneous drowsiness and sleep. J Vet Intern Med 22: 630-638.

Winwright, D., Elston, H., Hall, C. 2015. The impact of paddock design on the behaviour of the domestic horse (Equus caballus). Proceedings of the 3rd International Equine Science Meeting, Germany. ISBN 978-3-95625-000-2

Wöhr, A-C., Kalus, M., Reese, S., Fuchs, C. and Erhard, M. 2016. Equine sleep behaviour and physiology based on polysomnographic examinations. Equine Veterinary Journal 48. Supplement 50 (Abstract): 9

Wolff, A., Hausberger, M., Le Scolan, N. 1997. Experimental tests to assess emotionality in horses. Behavioural Processes 40: 209-221.

World Society of Aquariums and Zoos (WAZA). 2015. Towards Positive Welfare. Vol 16, pp 1. Yarnell, K., Hall, C. and Billett, E. 2013. An assessment of the aversive nature of an animal management procedure (clipping) using behavioral and physiological measures. Physiology \& Behavior, 118, 32-39.

Yarnell, K., Hall, C., Royle, C., Walker, S. 2015. Domesticated horses differ in their behavioural and physiological responses to isolated and group housing. Physiology and Behavior 143: 51-57. Yeon, S.C. 2012. Acoustic communication in the domestic horse (Equus caballus). Journal of Veterinary Behavior 7: 179-185.

Young, RJ. 1999. The Behavioural requirements of farm animals for psychological wellbeing and survival. In F. E. Dolins (Ed.) Attitudes to Animals: Views in Animal Welfare. Cambridge University Press: Cambridge. Pp77-100. 